\title{
Characteristics Study of Language Education Center in Korea University
}

\author{
Meiping $\mathrm{He}$ \\ School of Languages and Literature \\ Harbin Institute of Technology (Weihai) \\ Weihai, China
}

\author{
Mingzi Huang \\ School of Languages and Literature \\ Harbin Institute of Technology (Weihai) \\ Weihai, China
}

\begin{abstract}
The Korean Language Education Center, also known as the Korean Language School in Korea, is a branch of the International Language Institute at Korea University, which is one of the highest in the country, both in terms of teachers and hardware equipment. This thesis is mainly aimed at the historical features and the use of teaching materials of Korean language schools in Korea University. At the same time, this page combines "interesting Korean language 2"to study the teaching mode of Korean College. The Korean college is not only the top in Korea, with national characteristics, a preferred institution for learning languages, but also has compiled the Korean language teaching material with Korea's major characteristic. While large and excellent teachers explore the formation of an effective, suitable for foreign learners of the teaching model through a long period of teaching practice.
\end{abstract}

Keywords-Korea University; Korean language school; historical features; Korean textbooks; teaching mode

\section{INTRODUCTION}

With the development of international economy, politics and culture, the relations and exchanges between countries are becoming more and more close, no matter which one country can only carry out the struggle and development in its own territory, the world has entered the living mode of global development, and the exchange of language between countries has become one of the basic requirements for international communication and common development. This requires each country to set up corresponding language learning institutions, called language schools, to provide foreign learners with the opportunity to learn their own language.

In many universities in Korea, language schools are essential components. Non-Korean major foreign students, if you want to go to Korea University to receive undergraduate teaching, must first be in the language school to receive at least a year or so of linguistic education, so as to ensure that the university and South Korean students in the course of the process does not appear due to the language of the difficulties and communication difficulties caused by the classroom. Therefore, the language Academy plays an important role in learning and interpersonal communication. This makes the language school in the teacher strength, teaching material preparation, teaching mode and other aspects of the requirements cannot be ignored, each of the schools should have certain teachers, the preparation of their own textbooks, groping to explore the teaching model with their own characteristics.

\section{THE HISTORY AND CHARACTERISTICS OF KOREAN LANGUAGE SCHOOL}

Korea University was established in 1905, under the background of national crisis and the loss of sovereignty. It is the birthplace of the anti-Japanese struggle, national independence and modern knowledge for South Korea. After the establishment of the university of Korea, at every turning point in history, the university has trained tens of millions of talents to safeguard the development of national and national security, at the same time set up new coordinates for the country and the nation. In the process of industrialization and nationalization, Korea university, as the university with the most Korean characteristics, is trusted and loved by the people.

The Korean Language Education Center of the International Language Institute of Korea University was founded in the 1986, March, which follows the development of South Korea. It is a professional organization for Korean Education which aims at demonstrating Korean language and rich Korean culture widely to the world international field. So far, about 25,000 overseas compatriots studying Korean, Korean history, and the inherent Korean culture in South Korea's cultural education Center are now each year with approximately 3000 students studying Korean and Korean culture courses. The Korean Language culture and education Center is famous for its educational process that reflects the diverse requirements of learners, the strong teachers who specialize in Korean language education, teaching materials that fully reflect the characteristics of Korean language, modern methods of teaching, and a colorful atmosphere of instruction. At the beginning of the century, the Korean Culture and Education center complied with the requirements of language teaching, with the most comfortable educational environment and the most advanced media equipment, in order to enable foreign learners and compatriots abroad to learn Korean and Korean culture better, and constantly committed to the development of new educational methods and teaching materials, Is the leader of Korean language education.

In terms of language education, the Korean Culture and Education Center is a language educational course which combines the learners' language level stage, based on the professional knowledge, develops the teaching material to 
carry on the system by oneself, simultaneously should the learner's language level and the request, will the audition, the conversation, the reading, the writing and so on the appropriate synthesis, enhances the In educational environment and media equipment, all course handouts are arranged in specialized classrooms that can accommodate more than, and large and medium-sized classrooms have video handouts, computers and other equipment, learners can carry out a variety of curriculum learning, in the professional Korean teachers. All teachers are based on the theory of linguistic education and the characteristics of Korean language. To consider the actual education scene, develop effective Korean language education methods of professional language teachers; in Korean culture, the language school is not only the place to learn Korean, but also let learners understand the real life of Korea, experience customs, A place to learn about Korean diversity. Through the tour of the traditional art, the learners can learn about the history, the present and the future through the activities of the ceramics production, taekwondo, calligraphy and four objects games, and can experience all kinds of meaningful Korean life through the Student Service Association of Korea University.

The Korean language courses in the language schools are mainly divided into formal courses, school courses for teenagers ' holidays, Korean-language intensive courses for the summer holidays, special courses for Japanese learners, and trusteeship courses. It is based on the formal curriculum, for the year above the foreign scholars and overseas compatriots for the enrollment, the year of spring, summer, autumn, winter 4 semester courses, according to the Korean level from the 1 level to 6 the level of Korean language level education, where 6 ends of students can enter the workshop study. In addition to the Korean language course, the Korean formal curriculum offers a wide variety of special events and associations to learners, as well as cultural and internship courses each semester to increase the learners ' understanding of Korea. One of the community activities have Korean song class, Seoul City visit classes, cultural experience classes, travel and internship activities are art galleries, folk village, Love Treasure Park, Sorak, cultural courses have pickled kimchi, ceramic carving, folk games, watching a variety of performances. Through these activities and associations can improve learners ' interest in Korean language, increase their understanding of Korean and Korean culture, meet the requirements of different learners.

\section{THE CHARACTERISTICS OF TEACHING MATERIALS IN KOREAN LANGUAGE SCHOOL}

Korean Language and Culture Education Center of Korea University since the establishment of the many years, the corresponding education process in response to the requirements of learners has developed a variety of Korean textbooks, "How to improve Korean language ability," "foreign language learning for foreigners", "Korean professional learning" and so on.

Korean teaching materials are different in various universities, each of which has its own characteristics. The Korean University Language School in a variety of textbooks in the "interesting Korea" as a textbook topic, a total of 6, respectively, is the primary up and down, intermediate up and down, high and low, by the Korean University of Korealanguage culture and Education Center personally compiled, Korean culture and education professional Professor as a supervision committee, the Library published. "Interesting Korean" is the language school in the teaching process according to the actual experience and the teaching site and the results of the development of educational achievements compiled. The main feature of this book is the understanding of the structure of the Korean language and a wide range of oral dialogue exercises, based on learner-centered, improve learners in the complex and diverse real life to successfully carry out a natural and fluent Korean communication ability.

The composition of the content of the "interesting Korean" textbook is compiled in the same pattern, each book is divided into class, each class has its own teaching objectives, in the overall TOC will be the subject of learning for each lesson, activity content, grammar, listening, dialogue, culture, respectively, in Korean and English explained, Each lesson is composed of five major parts, namely, the outline of the lesson, dialogue of the text, oral practice, activities, grammar. The main premise of the course is to guide learners to understand the subject to be studied in advance; the dialogue of the text is divided into three parts, each of which is explained by the vocabulary of the text. The spoken language exercises are made up of exercises, each part of which is connected to the following syntax, with the new English-Korean vocabulary explained the activity part is divided into audition, conversation, reading and writing, and also adds cultural knowledge and selfevaluation.

The primary purpose of education is to allow beginners to master the pronunciation of Korean-notes, to write a simple theme, to greet each other briefly, to introduce themselves, to shop in supermarkets, to ask for directions, to establish an agreement, the most basic and commonly used Korean dialogues in daily life. The main purpose of the primary teaching is to master the pronunciation and vocabulary on the basis of the daily life and closely linked to the canteen, shops, post office and other topics as the main content, so that learners can independently carry out some of the daily use of high rate of conversational practice and article writing. Learners from the primary into the middle, have not felt their own in the conversation has a great improvement, this is because the primary focus on the pronunciation and vocabulary, for learners to enter the intermediate will not be the same as the primary by pronunciation and vocabulary, which is a transitional phase, From this stage it will increase the actual dialogue scenes in Korean life, let learners gradually close to the reality of Korean society.

The middle of the main teaching content from a simple daily dialogue into the workplace, career, school life, asking students to start with the social, abstract theme for a simple scene conversation, but also to increase the vulgar talk about culture, South Korea's famous festivals and customs content, began to cultivate the ability of students to communicate independently, in the middle of the social, abstract theme of content to increase news, media information, so that learners can distinguish between spoken and written language differences, In the workplace life can use appropriate 
workplace life language to carry out basic conversation and processing business, while gradually improve writing ability.

From the advanced stage of the Korean language, the teaching field model also has the normal form of the previous routine, teaching content began to increase political, economic, social, cultural and other topics of content, to cultivate learners to distinguish between formal and informal language use of the ability and self-expression ability, able to master and understand the Korean language papers, reports, Debates and other content, improve the ability to read and publish, broaden the political, economic, historical and cultural knowledge; After the high level of learning in Korean, not only to understand the political and economic aspects of Korea, but also to be able to debate the subject, to express their views and opinions, to improve their own completion of the report, the paper, The ability of professional writing and cultural works to conduct appropriate conversations, exchanges and debates with Koreans on the right occasions. After completing the advanced Korean language, learners can make full use of Korean to carry out fluent conversation, writing, of course, this is not the end of language learning, learners will continue to strengthen the tone of Korean language, tone, and more exchanges with Koreans, so that their gradual integration into the Korean cultural circle.

"Interesting Korean" is equivalent to the Chinese University Korean language major use of intensive reading materials, is based on vocabulary and grammar, the difference is that Chinese university Korean language textbooks are compiled in Chinese, for language learners, this is not a good strategy, The Korean language school textbooks are basically from the Korean language plus English translation, which is conducive to increase the learners ' awareness of exploration and cultivate a good Korean learning environment. Besides the interesting Korean language, the teaching materials of Korea University are equipped with such books as "Korean Spoken language learning for foreigners", "learning Korean grammar skillfully" and "How to write good Korean language".

\section{Characteristics OF TEACHING Methods IN KOREAN LANGUAGE SCHOOL}

Teaching efficiency in addition to textbooks, another important factor is the teaching method of teachers, the key point of language learning is to teach in the mother tongue or the second language, the Korean University in the classroom in the teaching of the main use of the second language as the medium of instruction, student-centered, teacher-assisted teaching mode, For beginners, this mode of teaching, although a little difficult, but the teacher will be based on the Korean language level appropriate to explain, this is conducive to improving students ' ability to audition, for students to cultivate a good Korean learning environment.

The educational process of Korean college is mainly divided into five stages of introduction, explanation, practice, intensification and summarization, which is embodied in teaching materials, teachers combine the contents of teaching materials and use these five stages flexibly. Take one of the lessons for example, the specific course is as follows.
Dialogue using the grammar you have learned.

Although ... But...

Import Phase: indirectly introducing learning content in a conversational manner

Description Phase: The describes the syntax that is learned, combined with the actual situation.

Example: (1)In Korea, although the fruit is delicious, it is too expensive.

South Korea life is tired, but very interesting.

(2) go to Qingdao every week. Every Sunday she calls her mother.

Practice Phase: Practice using the grammar you have learned.

Teacher: Do students often go shopping?

Student: I often go but don't buy much.

Teacher: What will Ma Nan do every holiday?

Ma Nan: Every holiday will be cleaned.

Use phase: The uses the knowledge of the grammar that is learned in a grouped manner to make a conversation between two people, or group publication.

End Stage: Teachers talk to students with questions answers, and then explain the problems that arise during the grammar learning process, and describe unfamiliar words, Leave homework.

In the previous example, we can see that teachers always take students as the center, each process interacts with students, so as to concentrate students ' attention and arouse students interest in learning. This mode of teaching can not only give students more practice of oral and communication opportunities, so that learners dialogue and evaluation, find themselves doing a good job and need to improve the place, but also can improve learners ' ability to think independently and organize language.

\section{CONCLUSION}

With the rise and development of Korean wave, more and more people come to South Korea to study Korean language and culture. Therefore, language school is increasingly important as the main professional institutions for the study of Korean language. Through the analysis of the history and characteristics of Korean college, the use of teaching materials and the characteristics of teaching methods, showing the University of Korea, whether from the historical characteristics, a variety of teaching materials development, or the current stage of education results are ranked among the top of the selection, hoping to provide a strong help for the future Korean learners.

Course scope and goals: page 8 Lesson Traffic 


\section{ACKNOWLEDGMENT}

This work was financially supported by the Research Foundation for Doctoral Scholars of Harbin Institute of Technology at Weihai (IDGA10002063)

\section{REFERENCES}

[1] [Korean] Kang Seung Hye, A needs analysis on development of a Korean textbook for Korean language learners, vol.28. Korean language education as a foreign language, 2003, pp.251-286.

[2] [Korean] Kim Seul, Analysis of Korean Language Schools' Educational Strategy. A scholarly paper, Chongshin University, 2015.

[3] [Korean] Kwon Na Young, Yonsei University Korean Language Institute, Korean Education, 2nd ed, vol. 16, 2005, pp.457-463.

[4] [Korean] Wang Jia, A Study on the Relationship in the Quality of Educational Service and the Satisfaction in Korean Language School (Focused on Chinese abroad students ), A scholarly paper, Yeungnam University, 2011.

[5] [Korean] Fun! fun! Korean2. Korean Language and Culture Center, Korea University,2008. 